2017-06

\title{
Distortional buckling of perforated cold-formed steel channel-section beams with circular holes in web
}

\author{
Li, Long-yuan
}

http://hdl.handle.net/10026.1/9109

10.1016/j.jmecsci.2017.04.001

International Journal of Mechanical Sciences

Elsevier BV

All content in PEARL is protected by copyright law. Author manuscripts are made available in accordance with publisher policies. Please cite only the published version using the details provided on the item record or document. In the absence of an open licence (e.g. Creative Commons), permissions for further reuse of content should be sought from the publisher or author. 
http://dx.doi.org/10.1016/j.ijmecsci.2017.04.001

Received 16 January 2017; Received in revised form 19 March 2017; Accepted 4 April 2017

International Journal of Mechanical Sciences 126 (2017) 255-260

Available online 05 April 2017

\title{
Distortional buckling of perforated cold-formed steel channel-section beams with circular holes in web
}

Wei-bin Yuan (yuanwb@zjut.edu.cn) and Nan-ting Yu (yunanting@ foxmail.com)

College of Civil Engineering and Architecture, Zhejiang University of Technology, Hangzhou, China

Long-yuan Li (long-yuan.li@plymouth.ac.uk)

School of Engineering, University of Plymouth, Plymouth PL4 8AA, UK

\begin{abstract}
This paper presents the numerical and analytical investigations on the distortional buckling of perforated cold-formed steel channel-section beams with circular holes in web. The numerical investigation involves the use of finite element methods. In the analytical analysis the distortional buckling model recommended in EN1993-1-3 is employed. The influence of the web holes on the distortional buckling behaviour and corresponding critical stress and moment of perforated cold-formed steel channel-section beams are discussed. Finally, a simple analytical formulation is proposed for evaluating the effect of hole size on the reduction of critical stress and critical moment of the channel-section beams with circular holes in web.
\end{abstract}

Keywords: Perforated, cold-formed, channel, distortional buckling, web opening, finite element.

\section{Introduction}

Thin-walled, perforated cold-formed steel (PCFS) sections are frequently used as structural members in residential buildings and for storage rack constructions. For example, in low and mid-rise building construction holes are pre-punched in structural studs to accommodate the passage of utilities in the walls and ceilings of buildings; whereas in steel storage rack constructions columns perforation patterns are provided to allow for variable shelf configurations. The buckling behaviour of PCFS sections is influenced not only by the reduction of cross-sectional properties but also by the stress concentration caused due to perforations. Similar to common cold-formed steel (CFS) sections, PCFS sections may also exhibit local, distortional, and global buckling modes when they are subjected to compressive and/or bending loads. However, because of the wide variety in the size and configuration of perforations, it is rather difficult to directly calculate the critical buckling stresses of PCFS sections [1].

Early work assessed the influence of a single hole on the elastic buckling of rectangular plates under compression [2]. It was found that the hole reduces the bending stiffness of the plate and causes the concentration of the axial stress in the plate strips adjacent to the hole. The work led to the development of approximation of elastic buckling stress for plates with holes by assuming the strips adjacent to the hole to act as unstiffened elements and the concept of effective width for predicting the post-buckling ultimate strength of plates with holes [3,4]. Davies et al. [5] developed a design method for PCFS sections subjected to axial and bending loads by using both experimental and numerical results, taking account of local, 
distortional and global buckling. Kesti and Mäkeläinen [6] presented a design method for gypsum-sheathed perforated steel wall studs, of which the failure mode was mainly controlled by distortional buckling. Dhanalakshmi and Shanmugam [7] compared the ultimate load-carrying capacities of perforated and non-perforated equal-angle CFS stub columns under axial and eccentric loads. By using both experimental and numerical results a simplified design formula was proposed to determine the ultimate load-carrying capacity of PCFS equal-angle stubs. Szabo and Dubina [8] evaluated an equivalent $\alpha$ imperfection factor for EN buckling curves to adapt them for sections with different perforation patterns. Freitas et al. [9] conducted a material and geometric non-linear analysis using ANSYS for typical sections of perforated stub columns manufactured in Brazil. The numerical results were compared with experimental data obtained by stub column tests. Sputo and Tovar [10], Tovar and Sputo [11] analysed the local and distortional buckling problems of PCFS studs using finite strip method and the critical loads obtained were used to calculate the ultimate strength of the PCFS studs by using the direct strength method. Experiments were carried out by Moen and Schafer [12] to quantify the relationship between the elastic buckling and tested responses of CFS columns with holes. Compression tests were conducted on 24 short and intermediate length CFS columns with and without slotted web holes. For each tested specimen, finite element buckling analysis was also carried out such that the influence of the boundary conditions and the hole on local, distortional, and global elastic buckling responses was examined. It was showed that slotted web holes could modify the local and distortional elastic buckling half-wavelengths, and may also change the critical elastic buckling loads. Experimental work was carried out by Crisan et al. [13] on upright members of two different cross-sections, with and without perforations to determine the ultimate strength for specimens of different lengths corresponding to local, distortional and global buckling. Material tests and imperfection measurements for the tested specimens were also performed. The effects of perforation positions on the load capacity of column members of lipped channel cross-section were investigated by Kulatunga and Macdonald [14] using both experimental and finite element numerical methods. The influence of perforations of various shapes on the buckling behaviour of CFS columns of lipped channel cross-section was examined by Kulatunga et al. [15] using finite element analysis method.

Finite strip method has been widely used for the buckling analysis of CFS members. The problem with the finite strip method is that holes cannot be easily modelled. In order to apply the finite strip method to PCFS sections, Casafont et al. [16] proposed an approach in which a reduced thickness of the perforated strip is applied to take into account perforations effect. A formulation was proposed for the reduced thickness that has been calibrated with loads obtained in the buckling analysis using finite element method. The accuracy was verified by carrying out analyses on real rack columns with different end conditions. Recently, the flexural behaviour, including the ultimate moment capacities and failure modes, of built-up CFS members with circular web holes was investigated by Wang and Young [17] using experimental methods. A total of 43 beams having ten cross-section sizes with different hole diameters were tested under four-point bending. Different approaches of determining the critical elastic local and distortional buckling moments including the influence of holes for the built-up open and closed sections were compared and discussed. The influence of web opening on the lateral-torsional buckling behaviour of CFS channel-section purlins was also examined by Ling et al. [18] using finite element method. More recently, extensive research has been carried out on the load bearing capacity of rack uprights subjected to combined axial and bending loads using different analysis methods, including design codes [19], experimental [20] and finite element numerical [21-23] methods. 
In this paper, the distortional buckling of PCFS channel-section beams with circular holes in web is investigated using finite element method. The influence of the web openings on the critical stress and critical moment of distortional buckling is examined. Finally, according to the EN1993-1-3 distortional buckling model, a simple analytical formulation is proposed for the prediction of critical stress and critical moment of distortional buckling of PCFS channelsection beams with circular holes in web.

\section{Finite element analysis of PCFS channel-section beams with circular holes in web}

Consider a PCFS channel-section beam with circular holes in web as shown in Figure 1. The depth of web, flange width, lip length, and thickness of the section are symbolised by $h, b, c$, and $t$, respectively. It is assumed that the circular holes of diameter $d$ are equally displaced in the web along the longitudinal direction of the beam. For the convenience of discussion, the beam length is assumed to be $L=n \pi \mathrm{d} / 2$, where $n$ is an integer, representing the total number of holes in the web. This implies that, in the web strip of openings the total opening area is equal to the total solid area. The beam analysed is assumed to be simply supported at its two ends, and subjected to a pure bending about it major axis. Figure 2 shows a typical mesh of shell elements used in the analysis for the beam. The displacement boundary conditions are applied to the nodes at the two end sections of the geometrical model. All nodes at both end sections are assumed to have zero lateral displacement, zero transverse displacement, and zero rotational displacement about the longitudinal axis. To avoid the rigid displacement in the longitudinal axial direction a node located at the neutral plane at one of the end sections is assumed to have zero axial displacement. The bending moments loaded at the two end sections are applied by the line distribution forces defined on the web, flange, and lip lines, in which the forces are assumed to be uniformly distributed on the two flange lines ( $\sigma_{y} t$ for upper flange and $-\sigma_{y} t$ for lower flange), linearly distributed on the web (from $\sigma_{y} t$ to $-\sigma_{y} t$ ) and lip (from $\sigma_{y} t$ to $\sigma_{y} t(1-2 c / h)$ for upper lip and from $-\sigma_{y} t(1-2 c / h)$ to $-\sigma_{y} t$ for lower lip) lines, as shown in Figure 2, respectively. The material properties of the beam are assumed as Young's modulus $E=210 \mathrm{GPa}$ and Poisson ratio $v=0.3$, yields stress $\sigma_{y}=390 \mathrm{MPa}$. The linear buckling analysis is performed by using the commercial software ABAQUS.

In order that the obtained lowest eigen-value represents indeed the critical stress or the critical moment of distortional buckling mode, the dimensions of the channel section to be analysed are carefully chosen. Figure 3 shows a log-based plot of the buckling curve of the chosen channel section without web openings obtained from finite strip method, in which $M_{c r}$ is the critical moment of the beam subjected to pure bending and $M_{y}$ is the corresponding yield moment. It can be seen from the figure that, the dominant buckling mode is the local buckling for beam length less than $220 \mathrm{~mm}$, the distortional buckling for beam length between $220 \mathrm{~mm}$ and $1200 \mathrm{~mm}$, and the lateral-torsional buckling for beam length greater than $1200 \mathrm{~mm}$, respectively. The lowest critical moment of local buckling is found to be much higher than that of distortional buckling. It is observed from the figure that, as long as the length of the beams analysed is in the range of $300 \mathrm{~mm}$ to $1750 \mathrm{~mm}$, the lowest critical stress will be that of distortional buckling. It should be noted that, if the PCFS channelsection beams have identical hole size and hole spacing, the beam length must follow the formula of $L=n \pi d / 2$, indicating that the beam length is a discrete function.

Existing experience showed that the element size can affect the accuracy of obtained critical stresses. The sensitivity analysis of element mesh on the obtained critical stresses or critical moments is thus carried out by using a number of trials with different mesh sizes. It is found 
that when the maximum element size in the mesh is equal or below $10 \mathrm{~mm}$, the eigen-values associated with the first two lowest buckling modes obtained from different meshes are almost the same. Hence, in the present finite element analysis the mesh used for different beam lengths is controlled by restricting the maximum element size not exceeding $10 \mathrm{~mm}$.

Figure 4 shows the buckling curves of the four typical PCFS channel-section beams with circular holes of different sizes in web, in which $M_{c r}$ is the critical moment of distortional buckling of the beam and $M_{y}$ is the yield moment of the beam with no holes. It can be seen from the figure that all of the curves have a similar variation patter. In each case the critical moment of the distortional buckling varies slightly around the local minimum point, representing the interfering effect between the beam length and the half wavelength of distortional buckling mode. It is observed that the larger the holes the smaller the critical moment. This seems to be expected as the larger the holes, the weaker the web to resist the rotation of the compressed flange/lip element and thus leads to a lower critical moment. The half wavelength associated with the critical moment (i.e. the minimum point in each curve) is found to increase with the hole size, indicating that the web opening affects not only the critical moment but also the half wavelength of distortional buckling mode. Note that the roughness of the curves shown in Fig.4 is due to the beam length which has to follow the formula of $L=\mathrm{n} \pi \mathrm{d} / 2$ to ensure the beams of different lengths have the same hole size and hole spacing. Figure 5 shows the typical distortional buckling modes of a PCFS channelsection beam at three different beam lengths, obtained from the finite element analysis. It is evident from the figure that the distortional buckling modes with one, two and three buckling waves, respectively in three different beam lengths are all characterised by the rotation of compression flange about the web-flange junction.

\section{Distortional buckling modelling of PCFS channel section beams with circular holes in web}

The distortional buckling of CFS sections is commonly categorized by the translation and rotation of the corners of the cross-section [24-28]. The distortional buckling of a flexural member such as channel- or zed-section normally involves the rotation of the compression flange and lip about the flange-web junction. The web experiences a flexure at the same halfwavelength as the buckled flange-lip element. In Eurocode 3 [25], the design of compression elements with intermediate or edge stiffeners is based on the assumption that the stiffened element behaves like a strut supported by an elastic foundation with a spring stiffness along the length that depends on the boundary conditions and the flexural stiffness of the adjacent plane elements of the cross-section (see Figure 6a). The elastic critical buckling stress of the stiffened elementikexpressed as follows [25],

$$
\sigma_{c r}=\frac{{ }^{2}}{A_{s}}
$$

where $\sigma_{\mathrm{cr}}$ is the critical stress of distortional buckling, $K$ is the spring stiffness per unit length, $E I_{s}$ is the bending rigidity of the stiffened element, $I_{s}$ is the second moment of the area of the stiffened element about the axis parallel to flange, and $A_{s}$ is the area of the stiffened element. For the PCFS channel section discussed in the present study holes are only located in the web and thus Eq.(1) could be also applied but the spring stiffness need to be modified to take into account the effect of web openings. Hence, when the local buckling of the compressed flange and lip is ignored, $A_{s}$ and $I_{s}$ of the stiffened element can be calculated as follows [25], 


$$
\begin{aligned}
& A_{s}=\left(\frac{b}{2}+c\right) t \\
& I_{s}=\frac{b t^{3}}{24}+\frac{e^{2} b t}{2}+\frac{t c^{3}}{12}+c t\left(\frac{c}{2}-e\right)^{2}
\end{aligned}
$$

where $e$ is the vertical distance of the centroid point of the stiffener element away from the flange and is expressed as follows,

$$
e=\frac{c}{b+2 c}
$$

In order to determine the spring stiffness $K$ of the PCFS channel section, the web strip where the holes are located is assumed to have a different bending rigidity from the other part of the section (see Figure 6b). By using a unit load applied at the centroid point of the stiffened element where the spring is located to the whole cross-section similar to that proposed in [27],

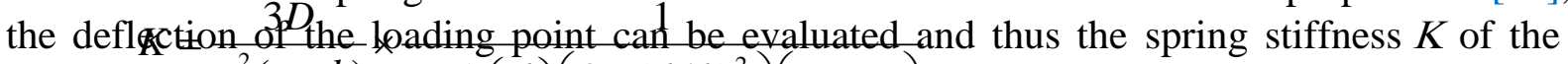

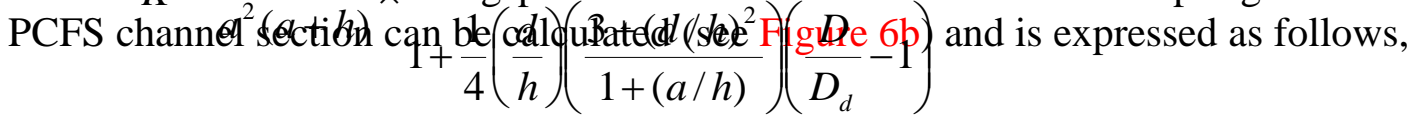

\[ a=b-\frac{b^{2}}{4(b+2 c)} \text { is the horizontal distance of the centroid point of the stiffened element } \]
where
\[ D=\frac{E t^{3}}{12\left(1-v^{2}\right)} \text { and } D_{d}=\frac{\alpha E t^{3}}{12\left(1-v^{2}\right)} \text { are the flexural rigidity of the strips } \]
away from the web,

with and without openings, respectively, and $\alpha$ is a reduction factor to be determined. It is obvious that if $d=0$ then $K=3 D /\left(a^{3}+a^{2} h\right)$, which represents the spring stiffness of the channel section with no holes in web. Note that, a smear model has been used in the derivation of Eq.(5), in which the web is split into three strips. The openings are located only in the mid-strip. The effect of openings on the flexural rigidity of the mid-strip is modelled by using the overall reduction factor $\alpha$.

Eqs.(1) and (5) provide a simple calculation method for the critical stress of distortional buckling of PCFS channel-section beams with circular holes in web under pure bending. The critical moment $2 f_{c r}$ the section can be calculated as follows,

$$
M_{c r}=\frac{2 r_{c r} \text { red }}{h}
$$

where $M_{c r}$ is the critical moment of distortional buckling and $I_{r e d}$ is the second moment of

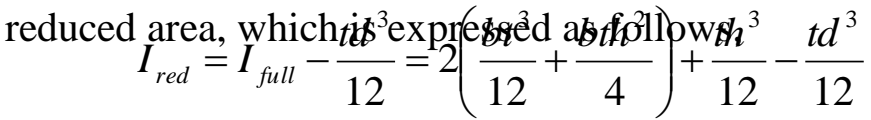

where $I_{\text {full }}$ is the second moment of the area of the channel section without holes in web. Of the particular interest is the effect of the hole size on the critical stress and critical moment of distortional buckling. Note from Eq.(1) that, the ratio of the critical stresses between PCFS and CFS channel-section beams can be expressed as follows, 


$$
\frac{\sigma_{c r, d}}{\sigma_{c r, o}}=\sqrt{\frac{K_{d}}{K_{o}}}=\frac{1}{\sqrt{1+\frac{1}{4}\left(\frac{d}{h}\right)\left(\frac{3+(d / h)^{2}}{1+(a / h)}\right)\left(\frac{1}{\alpha}-1\right)}}
$$

where $\sigma_{\mathrm{cr}, \mathrm{d}}$ and $\sigma_{\mathrm{cr}, \mathrm{o}}$ are the critical stresses of distortional buckling of the CFS channel sections with and without holes in web, $K_{d}$ and ${ }_{3} K_{o}$ are the spring stiffness per unit length in the CFS channel sections with and withlout holes in web, respectively. Similarly, for the critical molhent, $\frac{\text { it }}{M_{c r, o}}=\frac{I_{\text {yriel }}}{I_{\text {full }}} \sqrt{\frac{K_{d}}{K_{o}}}=\frac{12 I_{\text {full }}}{\sqrt{1+\frac{1}{4}\left(\frac{d}{h}\right)\left(\frac{3+(d / h)^{2}}{1+(a / h)}\right)\left(\frac{1}{\alpha}-1\right)}}$

where $M_{c r, d}$ and $M_{c r, o}$ are the critical moments of distortional buckling of the CFS channel sections with and without holes in web, respectively. Figure 7 shows a comparison of the critical moments calculated from Eq.(9) and those obtained from the finite element analysis for six different hole sizes. It can be seen from the figure that, among three selected $\alpha$ values, $\alpha=0.57$ gives a best fit to the finite element data; while $\alpha=0.65$ and $\alpha=0.50$ provide underand slightly overestimated variations. Physically, $\alpha=0.50$ represents the approach of equal width, which can be applied to the case of square holes; while for circular holes a slightly higher $\alpha$ value is required because of the section variation of the web post. This is why $\alpha$ $=0.57$ has a better fitted result. The critical stress and critical moment of distortional buckling of CFS members can be obtained using various analytical methods. The comparison shown in Figure 7 demonstrates that the critical stress and critical moment of PCFS channel-section beams with circular holes in web can be calculated by using the reduction factor defined by Eqs. (8) and (9) if the critical stress and critical moment of the corresponding CFS channelsection beams are known.

\section{Conclusion}

This paper has presented a study on the distortional buckling of PCFS channel-section beams with circular holes in web by using both numerical and analytical methods. The numerical analysis has been performed using finite element method; whereas the analytical analysis has been accomplished using the EN1993-1-3 distortional buckling model. The influence of the web openings on the distortional buckling behaviour and corresponding critical stress and critical moment of PCFS channel-section beams subjected to pure bending have been examined. From the obtained results the following conclusions can be drawn:

- The critical moment of distortional buckling of PCFS channel-section beam with circular holes in web decreases with increased hole size, but the half wavelength associated with the critical moment increases with increased hole size.

- The effect of circular holes in web on the critical moment of distortional buckling of PCFS channel-section beams can be interpreted as their effect on the rotational restraint to the compressed flange-lip system by using EN1993-1-3 distortional buckling model.

- The reduction of the rotational restraint of the web to the compressed flange-lip system due to the circular holes in web can be estimated using the concept of equivalent width with taking into account the section variation of the web post. 
- The web openings have two-fold effects on the critical moment of distortional buckling of PCFS channel-section beams with circular holes in web. One is due to the reduction of rotational restraint mentioned above; the other is owing to the reduction of the second moment of the area of the web.

\section{References}

[1] Moen CD, Schafer BW. Elastic buckling of cold-formed steel columns and beams with holes, Engineering Structures 2009; 31(12): 2812-2824.

[2] Schlack Jr. AL. Elastic stability of pierced square plates, Experimental Mechanics 1964; 4(6): 167-172.

[3] Yu WW, Davis CS. Cold-formed steel members with perforated elements, Journal of Structural Division (ASCE) 1973; 99(ST10): 2061-2077.

[4] Miller TH, Peköz T. Unstiffened strip approach for perforated wall studs, Journal of Structural Engineering (ASCE) 1994; 120(2): 410-421.

[5] Davies JM, Leach P, Taylor A. The design of perforated cold-formed steel sections subject to axial load and bending, Thin-Walled Structures 1997; 29(1-4): 141-157.

[6] Kesti J, Mäkeläinen P. Design of gypsum-sheathed perforated steel wall studs, Journal of Constructional Steel Research 1998; 46(1-3): 215-216.

[7] Dhanalakshmi M, Shanmugam NE. Design for openings in equal-angle cold-formed steel stub columns, Thin-Walled Structures 2001; 39(2): 167-187.

[8] Szabo IF, Dubina D. Recent research advances on the ECBL approach. Part II: interactive buckling of perforated sections, Thin-Walled Structures 2004; 42(2): 195-210.

[9] Freitas AMS, Freitas MSR, Souza FT. Analysis of steel storage rack columns, Journal of Constructional Steel Research 2005; 61(8): 1135-1146.

[10] Sputo T, Tovar J. Application of direct strength method to axially loaded perforated cold-formed steel studs: Longwave buckling, Thin-Walled Structures 2005; 43(12): 18521881.

[11] Tovar J, Sputo T. Application of direct strength method to axially loaded perforated cold-formed steel studs: Distortional and local buckling, Thin-Walled Structures 2005; 43(12): 1882-1912.

[12] Moen CD, Schafer BW. Experiments on cold-formed steel columns with holes, ThinWalled Structures 2008; 46(10): 1164-1182.

[13] Crisan A, Ungureanu V, Dubina D. Behaviour of cold-formed steel perforated sections in compression. Part 1-Experimental investigations, Thin-Walled Structures 2012; 61: 8696.

[14] Kulatunga MP, Macdonald M. Investigation of cold-formed steel structural members with perforations of different arrangements subjected to compression loading, Thin-Walled Structures 2013; 67: 78-87.

[15] Kulatunga MP, Macdonald M, Rhodes J, Harrison DK. Load capacity of cold-formed column members of lipped channel cross-section with perforations subjected to compression loading - Part I: FE simulation and test results, Thin-Walled Structures 2014; 80: 1-12.

[16] Casafont M, Pastor M, Bonada J, Roure F, Peköz T. Linear buckling analysis of perforated steel storage rack columns with the Finite Strip Method, Thin-Walled Structures 2012; 61: 71-85.

[17] Wang LP, Young B. Beam tests of cold-formed steel built-up sections with web perforations, Journal of Constructional Steel Research 2015; 115: 18-33.

[18] Ling JY, Kong SL, De'nan F. Numerical study of buckling behaviour of cold-formed Cchannel steel purlin with perforation, Procedia Engineering 2015; 125: 1135-1141. 
[19] Bernuzzi C, Maxenti F. European alternatives to design perforated thin-walled coldformed beam-columns for steel storage systems, Journal of Constructional Steel Research 2015; 110: 121-136.

[20] Kumar JVV, Jayachandran SA. Experimental investigation and evaluation of direct strength method on beam-column behavior of uprights, Thin-Walled Structures 2016; 102: 165-179.

[21] Bonada J, Pastor MM, Roure F, Casafont M. Distortional influence of pallet rack uprights subject to combined compression and bending, Structures 2016; (http://dx.doi.org /10.1016/j.istruc.2016.05.007).

[22] Ren C, Zhao XZ, Chen YY. Buckling behaviour of partially restrained cold-formed steel zed purlins subjected to transverse distributed uplift loading, Engineering Structures 2016; 114: $14-24$.

[23] Zhao XZ, Ren C, Qin R. An experimental investigation into perforated and nonperforated steel storage rack uprights, Thin-Walled Structures 2017, 112: 159-172.

[24] Hancock GJ. Design for distortional buckling of flexural members. Thin-Walled Structures 1997; 27(1): 3-12.

[25] EN1993-1-3. Eurocode 3 - Design of Steel Structures - Part 1-3: General rules Supplementary rules for cold-formed members and sheeting, 2006, BSI.

[26] Li LY, Chen JK. An analytical model for analysing distortional buckling of cold-formed steel sections, Thin-Walled Structures 2008; 46(12): 1430-1436.

[27] Li LY. Analysis of distortional buckling of cold-formed sigma purlins using EN1993-13, Journal of Constructional Steel Research 2009; 65(12): 2099-2102.

[28] AS/NZS. Australian/New Zealand Standard on Cold-formed Steel Structures - AS/NZS4600 (second ed.) Sydney (Wellington): Standards of Australian and Standards of New Zealand; 2005.

[29] Zhu J, Li LY. A stiffened plate buckling model for calculating critical stress of distortional buckling of CFS beams, International Journal of Mechanical Sciences 2016, 115116: 457-464. 


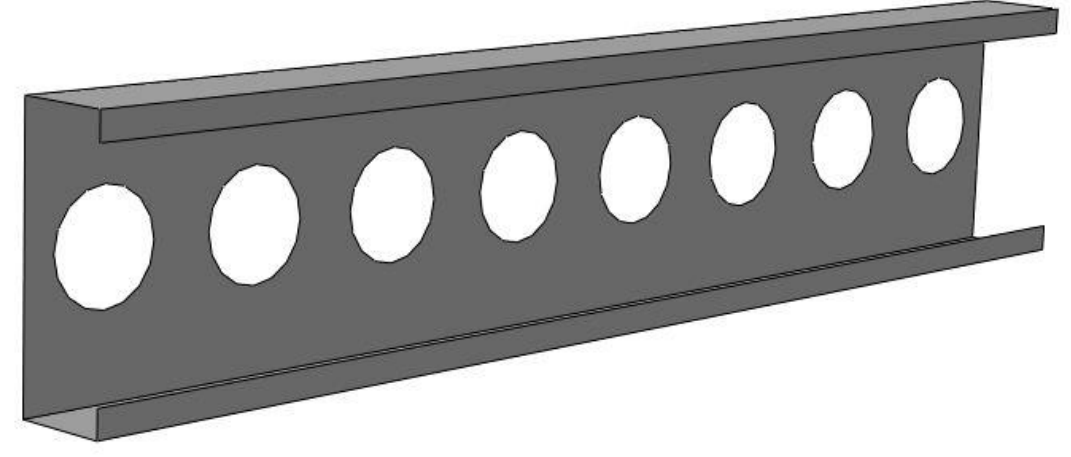

(a)

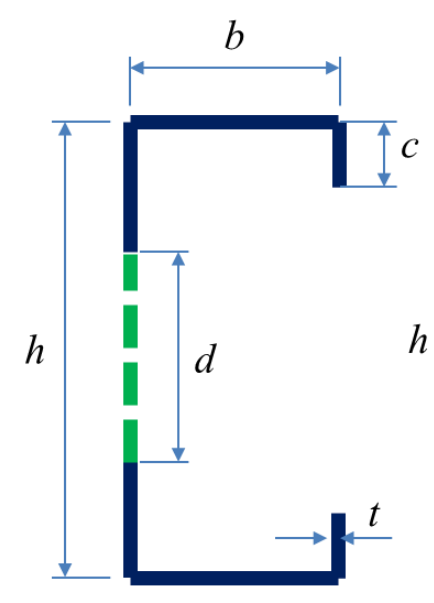

(b)

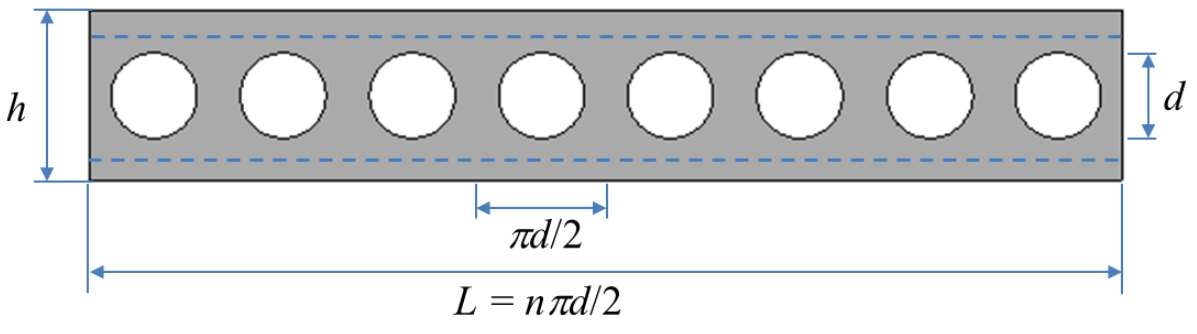

(c)

Fig.1. (a) PCFS channel-section beam. (b) Front view. (c) Side view.

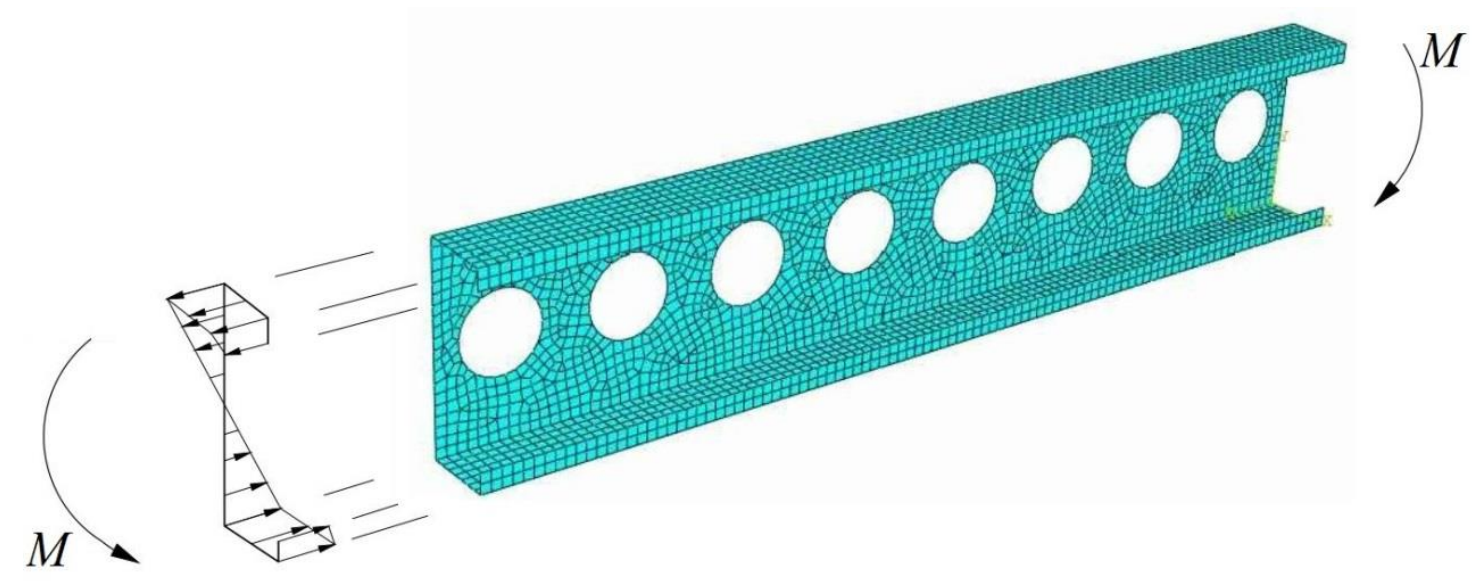

Fig.2. Finite element mesh of a PCFS channel-section beam with circular holes in web. 


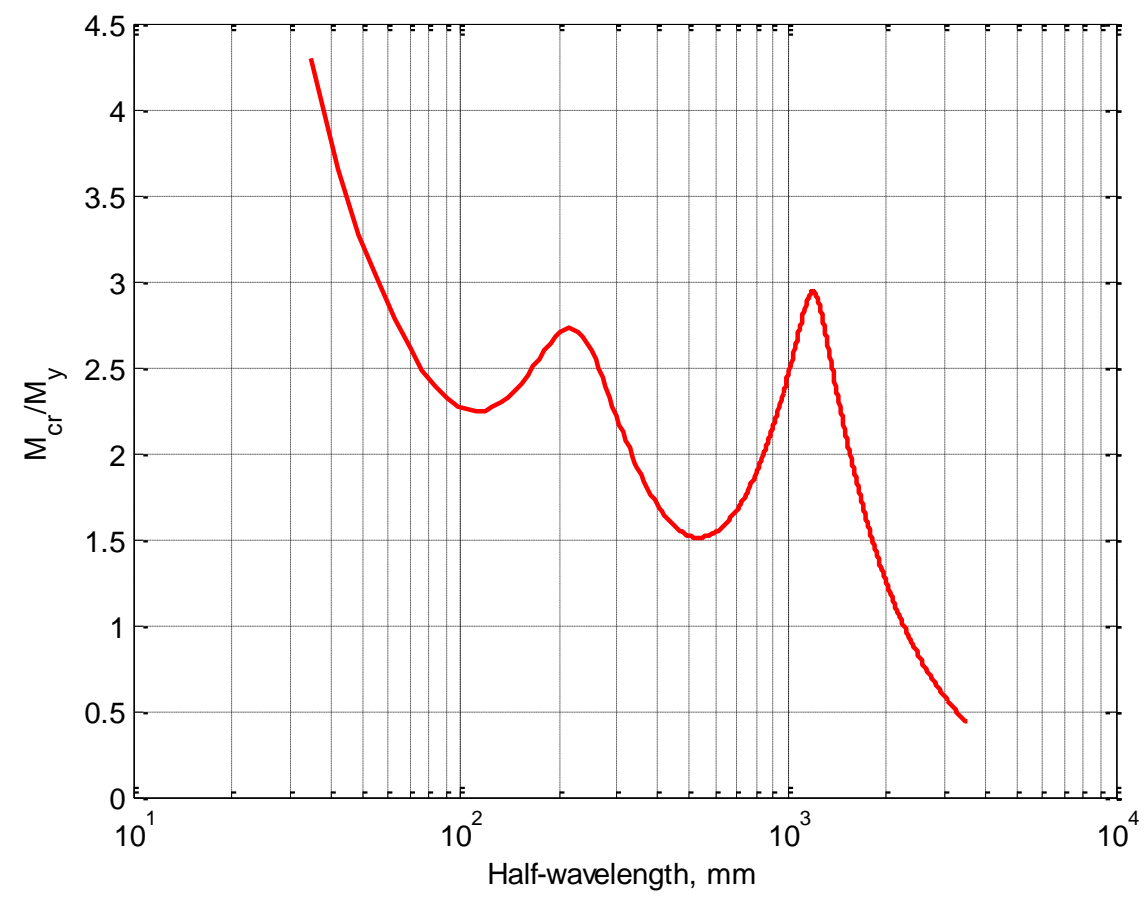

Fig.3. Buckling curve of CFS channel section chosen for FEA ( $h=200 \mathrm{~mm}, b=70 \mathrm{~mm}, c=$ $20 \mathrm{~mm}, t=2.5 \mathrm{~mm}, d=0, \sigma_{\mathrm{y}}=390 \mathrm{MPa}, \mathrm{M}_{\mathrm{y}}$ is the yield moment of the section).

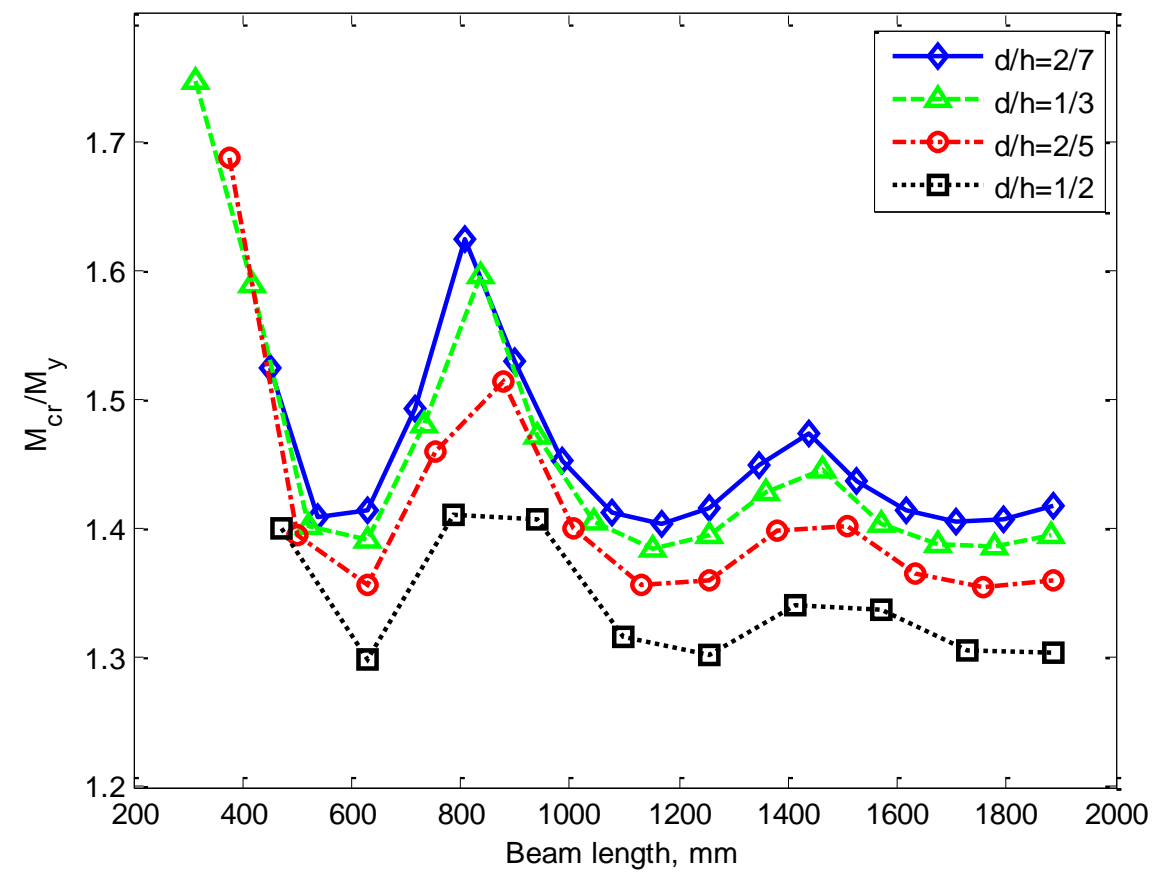

Fig.4. Distortional buckling curves of PCFS channel-section beams with circular holes in web ( $h=200 \mathrm{~mm}, \mathrm{~b}=70 \mathrm{~mm}, c=20 \mathrm{~mm}, t=2.5 \mathrm{~mm}, \sigma_{y}=390 \mathrm{MPa}, M_{y}$ is the yield moment of the section with no holes). 


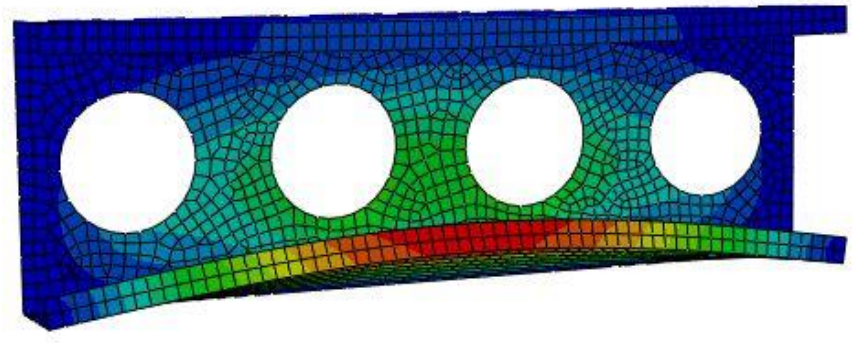

(a)

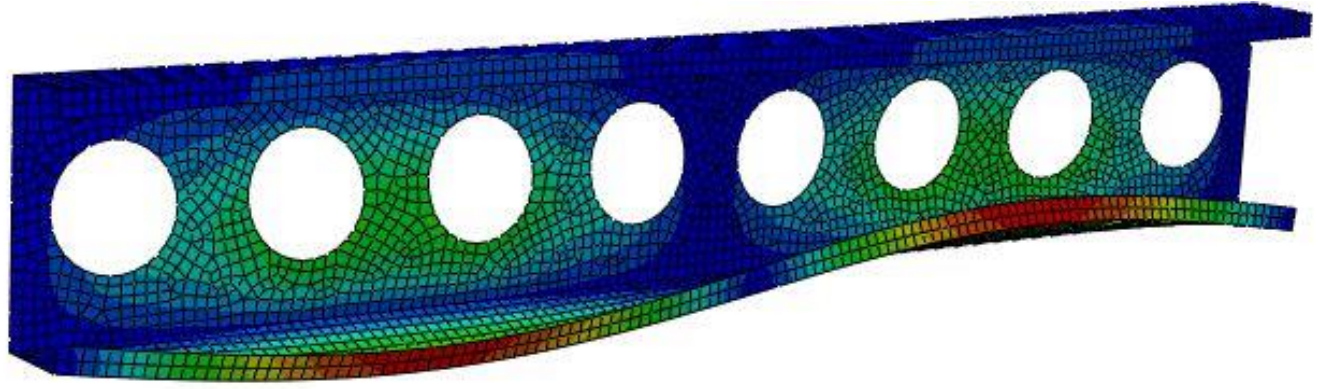

(b)

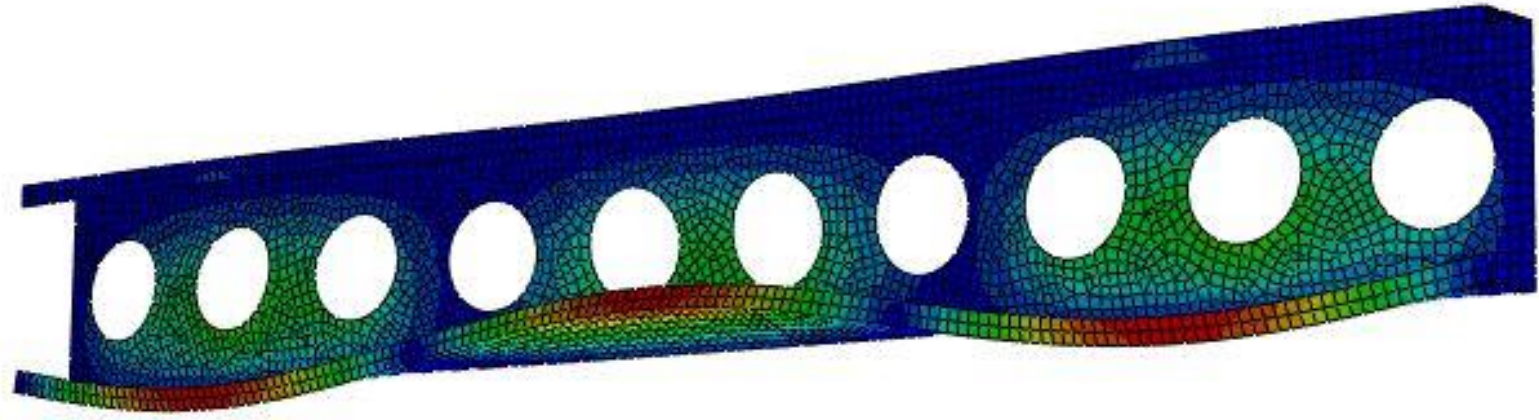

(c)

Fig.5. Distortional buckling modes of PCFS channel-section beams ( $h=200 \mathrm{~mm}, b=70 \mathrm{~mm}$, $c=20 \mathrm{~mm}, t=2.5 \mathrm{~mm}, d=100 \mathrm{~mm}$ ). (a) $L=628 \mathrm{~mm}$. (b) $L=1256 \mathrm{~mm}$. (c) $L=1570 \mathrm{~mm}$.

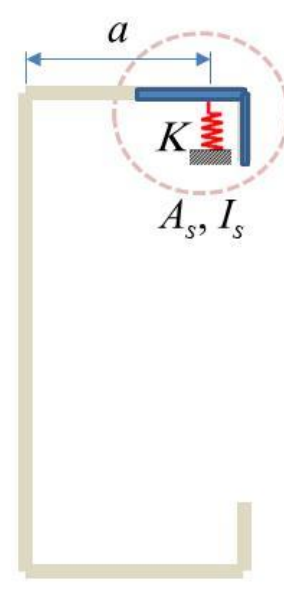

(a)

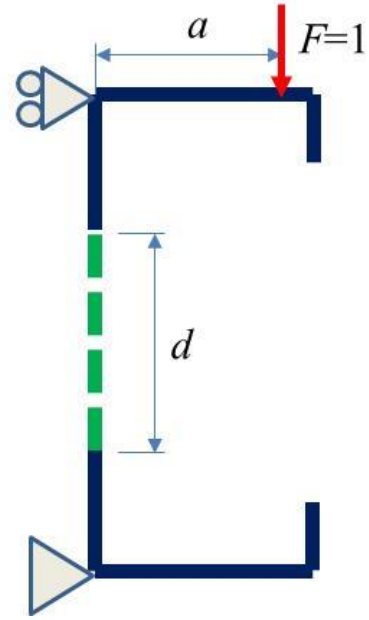

(b)

Fig.6. (a) EN1993-1-3 distortional buckling model. (b) Model used to determine spring stiffness. 


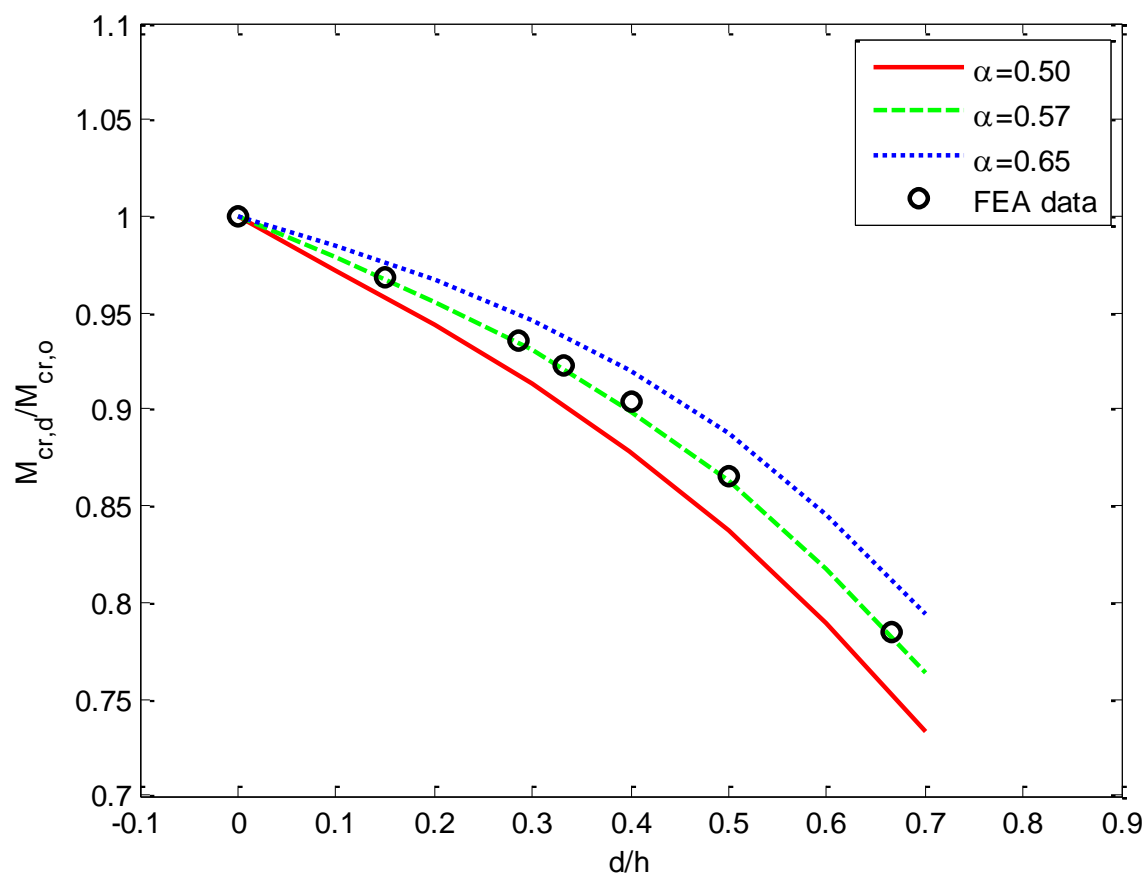

Fig.7. Comparison of critical moments of distortional buckling of PCFS channel-section beams with circular holes in web $(h=200 \mathrm{~mm}, \mathrm{~b}=70 \mathrm{~mm}, c=20 \mathrm{~mm}, t=2.5 \mathrm{~mm})$. 